\title{
Gullo's Syndrome (Benign Pancreatic Hyperenzymemia): Report of the First Two Cases in Basque Country
}

\author{
de Alba Iriarte $\mathrm{B}^{* 1}$, López $\mathrm{N}^{1}$, Rubio $\mathrm{A}^{1}$, Monzón $\mathrm{D}^{1}$, Zarco $\mathrm{MA}^{1}$ and Bujanda $\mathrm{L}^{2}$ \\ ${ }^{1}$ Osakidetza Basque Health Service, Donostia University Hospital, Clinical Biochemistry Laboratory, Donostia-San \\ Sebastián, Spain \\ ${ }^{2}$ Osakidetza Basque Health Service, Donostia University Hospital, Gastroenterology Department, Donostia-San \\ Sebastián, Spain
}

*Corresponding author: de Alba Iriarte B, Osakidetza Basque Health Service, Donostia University Hospital, Clinical Biochemistry Laboratory, Donostia-San Sebastián, Spain, Tel: 650203666, E-mail: baiargitxo@gmail.com

Citation: de Alba Iriarte B, López N, Rubio A, Monzón D, Zarco MA, et al. (2019) Gullo's Syndrome (Benign Pancreatic Hyperenzymemia): Report of the First Two Cases in Basque Country. J Case Rep Stud 7(4): 402. doi: 10.15744/2348-9820.7.402

Received Date: July 22, 2019 Accepted Date: August 26, 2019 Published Date: August 28, 2019

\begin{abstract}
Gullo's syndrome is a benign pancreatic hyperenzymemia that appears in healthy individuals and that is maintained over time, with fluctuations and transient normalization of pancreatic enzyme values in the absence of any evidence of clinical or morphological pancreatic disease. Its correct diagnosis is important to assure the carriers of the defect that there is no pancreas disease and to avoid unnecessary examinations, treatments and hospitalizations.
\end{abstract}

Keywords: Amylase; Benign Pancreatic Hyperenzymemia; Gullo's syndrome; Lipase

\section{Introduction}

Gullo's syndrome or Benign Pancreatic Hyperenzymemia is a new and rare entity characterized by a hyperenzymemia that is maintained over time, with increased and large fluctuations of pancreatic enzymes and transient normalization, in the absence of any evidence of clinical or morphological pancreatic disease [1]. It may occur sporadically or familiarly in healthy individuals [2].

Since this syndrome is benign, it's very important to rule out pancreatic disease, thus avoiding unnecessary examinations and useless hospitalizations and therapies [3-5].

Due to the novelty of the investigations in this field and the rarity of this disorder, we consider interesting its review through the study of these two cases.

\section{Cases Presentation}

\section{First case}

38-year-old male went to his family doctor suffering from nausea with vomiting of 15 days of evolution. He had no history of interest or regular medical treatment and his alcohol consumption was moderate. He denied pain at any time during the episode. He said he had been well for two days: no vomiting, no fever, no itching or stinging when urinating and normal bowel movements. The doctor asked for a fasting blood test to rule out any pathology and they arranged a consultation for three days later.

The results of the laboratory showed high values of serum amylase (221 U/L [10-125]) and serum lipase (178.9 U/L [13-60]), so acute pancreatitis was suspected, although the rest of the parameter values were normal, including alkaline phosphatase $90 \mathrm{U} / \mathrm{L}$ [40-129], Gamma-GT 57 U/L [10-71], AST/GOT 27 U/L [0-37] and ALT/GPT 37 U/L [0-41].

They referred the patient to the Emergency Department for a thorough evaluation. The physical and imaging scans were normal. The abdomen was soft and depressible, without pain on palpation or signs of peritoneal irritation, without masses or visceromegalies and a negative Murphy's sign. An apparently normal pancreas was seen on ultrasound. The analysis was repeated and it was seen that the result of the serum lipase had almost normalized: $109.7 \mathrm{U} / \mathrm{L}$. The amylase value was not determined. Since he was asymptomatic, he was discharged. It was decided he would be followed up by his family doctor and a pancreatic enzyme control analysis was requested. 
Two weeks later, the patient returned to consultation. He did not have nausea, vomiting, abdominal pain or constitutional syndrome, but the fasting blood test showed again an increase in pancreatic enzymes (amylase $313 \mathrm{U} / \mathrm{L}$ and lipase $344.8 \mathrm{U} / \mathrm{L}$ ), without further alterations. Afterwards in the Emergency Department, the physical examination turned out to be normal, and a new serum analysis showed normalized values of amylase (127 U/L) and lipase (48 U/L) (Figure 1). The veracity of these results was questioned, and determinations of both samples were repeated by different analytical equipment. The results, showing an intense fluctuation and normalization of the pancreatic enzymes within 8 hours, were confirmed.

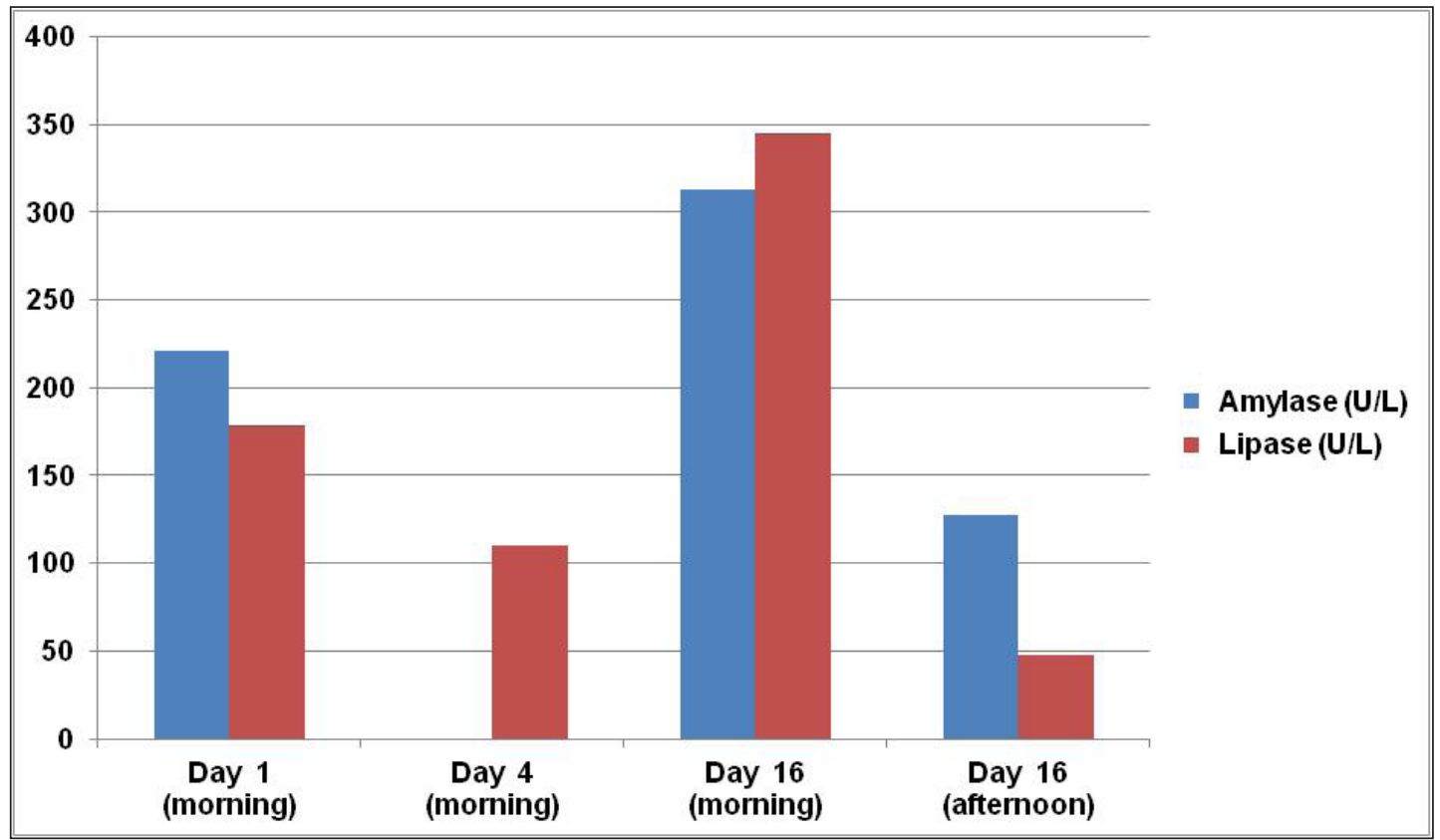

Figure 1: Serum amylase and lipase levels in four consecutive blood tests in first case. High fluctuation and normalization of the pancreatic enzymes is showed

\section{Second case}

62-year-old female has been evaluated periodically by her endocrinologist for more than ten years because of a hyperthyroidism due to Graves-Basedow's disease. She has been well controlled with fasting blood tests and treatment for her hyperthyroidism. She had no history of interest or another medical treatment and her alcohol consumption was very low.

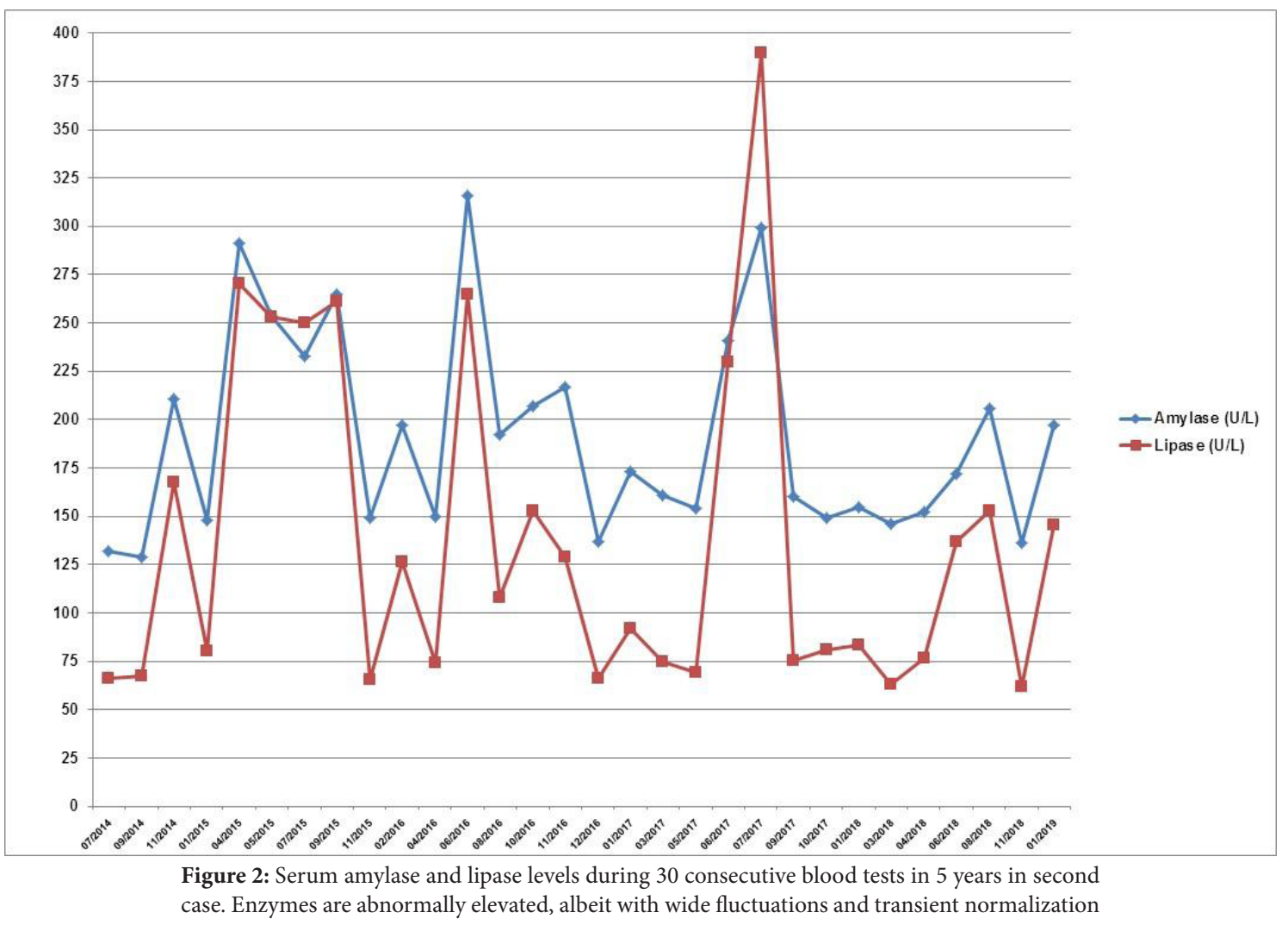


In the first consultation, the slight elevation of serum pancreatic enzyme values catched endocrinologist's attention: amylase (129 $\mathrm{U} / \mathrm{L}$ [10-125]) and lipase (63 U/L [13-60]). The patient was otherwise clinically asymptomatic, and the rest of the analytical results were normal; therefore, he demanded a new fasting analysis for the next day, the results of which appeared to be very different. The enzymatic values had increased considerably: amylase $240 \mathrm{U} / \mathrm{L}$ and lipase $205 \mathrm{U} / \mathrm{L}$. Liver function tests and abdominal ultrasound, including the pancreas, were normal. Thinking that she could suffer from some digestive pathology, the endocrinologist considered referring the patient to the gastroenterologist to carry out a more exhaustive follow-up.

These years he has frequently asked for fasting blood tests to observe the status and evolution of pancreatic enzymes in this patient. Sometimes the values have been very high, and other times the increase in amylase and lipase has normalized spontaneously without any explanation (Figure 2). The patient has followed a normal life, with frequent controls due to her hyperthyroidism. In addition to performing analysis periodically, she has undergone physical examinations and imaging tests in order to rule out any digestive disease. In blood tests, the rest of the parameters have been normal. The abdomen has not been painful to palpation and abdominal ultrasound, computed axial tomography and nuclear magnetic resonance have always been normal.

Doctors have not found a clinical justification to explain the elevations, fluctuations and normalizations of the pancreatic enzyme values of the patient.

\section{Discussion}

In 1986, the Italian gastroenterologist Dr. Lucio Gullo described for the first time a healthy man who had abnormally high serum pancreatic enzymes for a few months. He had been hospitalized for suspicion of pancreatic disease, but all biochemical and imaging tests were normal. It was thought that hyperenzymemia could be the expression of a pancreatic disease (chronic pancreatitis, tumor, etc.). However, no definite related pathology appeared. Since then, the main characteristics of this syndrome are known: elevation of pancreatic enzymes in serum, with fluctuations and/or transient normalization and absolutely normal pancreas demonstrated by imaging studies [6-8]. Later, Gullo published several articles on this entity and it is now known as Gullo's syndrome in his honor [9].

Elevated pancreatic enzymes generally mean pancreatic disease. However, Benign Pancreatic Hyperenzymemia is characterized by a persistent increase in pancreatic enzymes, such as amylase, lipase and isoamylase, without any clinical or pathological evidence of pancreatic disease. In $95 \%$ of the cases an increase of all pancreatic enzymes is evidenced, while in around 5\% there may be an elevation of amylase alone or, more rarely, of lipase [10]. Often, enzyme levels also show considerable fluctuation with transient normalization. After detection of hyperenzymemia, at least one year should pass before labeling it as Gullo's syndrome.

Gullo's syndrome can occur sporadically or in family distribution, and affects men and women in ratio of 1.5:1 [11]. There are also documented cases in children. The fact that this defect is detected in more than one member of the family has led to the hypothesis that there may be some genetic basis for Gullo's syndrome [2,11]. However, the molecular mechanism behind this entity is unknown. It is believed that there could be some defect in the basolateral surface of the acinar cells that cause an increase in the passage of enzymes into the blood. But it could also be caused by some effect of secretin in the Wirsung duct of the pancreas $[12,13]$.

There are very few publications on this subject, but since Dr. Gullo published his first study in 1986 [1], some investigations and inquiries have been made about this defect, mostly by Gullo.

In a published study it was investigated whether mutations in the cystic fibrosis gene (CFTR, cystic fibrosis transmembrane regulator) may have a role in the etiology of this form of hyperenzymemia. CFTR mutation can present as asymptomatic persistent pancreatic hyperenzymemia without any pancreatic insufficiency [14]. However, there is no increase in frequency of CFTR mutation in patients with Benign Pancreatic Hyperenzymemia as compared to general population $[15,16]$.

Some patients of Gullo's syndrome were evaluated for PRSS1 and SPINK1 mutation in a study by Gullo, but no PRSS1 mutation was detected and the frequency of SPINK1 variant was similar to the general population [17]. PRSS1 mutations have been linked with hereditary pancreatitis, whereas mutations in the SPINK1 gene have been associated with pancreatitis of different etiologies [18].

The possible relationship with celiac disease was also high and subjects with both conditions were studied [19]. However, none of them normalized their pancreatic enzymes levels after the gluten-free diet, so remains the question of whether this association is an occasional finding [14].

Another study investigated whether hyperenzymemia remains constant or varies throughout the day. The value of pancreatic enzymes in serum was determined during five consecutive days in a group of subjects with this syndrome, demonstrating that hyperenzymemia is not constant in most cases, since the values can vary from day to day and also present transient normalizations. The reason behind these frequent variations is not known [20].

In the first case described, the starting diagnostic suspicion was acute pancreatitis due to symptoms and high amylase and lipase values. However, some facts led the medical analyst to think about an entity different from liver, pancreas or bile duct diseases, without alcohol, biliary or pharmacological etiology, namely: normal transaminases, absence of pathological evidence in the 
imaging test and, especially, the existence of pancreatic enzyme fluctuations with transient normalization. In addition, following the repetitions of the analytical parameters and the imaging tests, the existence of tumors and macroamylasemia were ruled out. Macroamylasemia causes a chronic elevation of serum amylase levels without any pancreatic disease and is commonly associated with celiac disease, inflammatory bowel disease or autoimmune disease. Macroamylasemia should be suspected in the presence of persistent hyperamylasemia with low or normal amylasuria in a patient without alterations in renal function and with normal serum lipase levels. In Gullo's syndrome, instead, serum levels of both amylase and lipase are high, with large fluctuations.

The transient normalization of the pancreatic enzymes together with the lack of symptoms and the imaging tests that confirmed a completely normal pancreatic morphology, led to the diagnosis of Gullo's syndrome. However, the high fluctuations in enzyme concentrations in this asymptomatic patient were of clinical interest, and it was decided to keep the patient under follow-up to study his evolution.

In the second case described, the patient has been followed in consultations for more than a decade. In her fasting blood tests it's remarkable the elevation and variation of pancreatic enzymes levels, so that along these years her diagnosis has been considered as a case of chronic elevated amylase and lipase, with undetermined etiology or significance. By chance, during the follow-up of the first exposed patient, the authors of this review came to know that there was another case of possible Benign Pancreatic Hyperenzymemia: the case of a woman with longer medical history, but similar traits of asymptomatic elevation and fluctuating levels of amylase and lipase in fasting blood tests.

This case was studied carefully reviewing all the accumulated information. All the characteristics of the defect were fulfilled: hyperenzymemia that is maintained over time, with increased and large fluctuations of pancreatic enzymes and transient normalization, in the absence of any evidence of clinical or morphological pancreatic disease.

In both cases, the diagnosis of Gullo's syndrome has been determined by image data, clinical data and biochemical analysis data. Spontaneous variations in pancreatic enzyme levels have always been confirmed in analysis after an overnight fasting. The two cases have healthy feeding and drinking habits and they do not just take medications, so these variables are not influencing the results. No genetic analysis has been performed, because its conclusions are not clear yet today. It has been decided to keep the patients under follow-up to study their evolution.

\section{Conclusion}

The figure of the analyst is essential to confirm the results obtained and to reassure the clinician about its veracity and the reliability of the biochemical analysis equipment, given that the fluctuation of pancreatic enzymes in such a short period of time could be surprising.

The high concentrations of pancreatic enzymes in asymptomatic subjects are not only a laboratory finding, but also an event of clinical interest, since it raises doubts about whether the patient should undergo diagnostic procedures in search of non-benign pathologies. Frequently, these questions come from general doctors who detect elevated levels of amylase and/or lipase in routine blood tests.

The diagnosis of Benign Pancreatic Hyperenzymemia is important because it is a benign syndrome without pancreatic disease, which means that the performance of completely dispensable examinations and hospitalizations should be avoided, in order to prevent patients from suffering unnecessary worry and anxiety.

The authors consider that through the dissemination of articles on this subject, medicine may be able to detect these cases with greater brevity and effectiveness.

\section{Acknowledgments}

Thanks to Clinical Biochemistry Laboratory of Donostia University Hospital and to Faculty of Medicine and Nursing of the University of the Basque Country (UPV/EHU).

\section{References}

1. Gullo L (1996) Chronic nonpathological hyperamylasemia of pancreatic origin. Gastroenterology 110: 1905-8.

2. Gullo L (2000) Familial pancreatic hyperenzymemia. Pancreas 20: 158-60.

3. Gullo L, Cavicchi L, Tomassetti P, Spagnolo C, Freyrie A, et al. (1996) Effects of ischemia on the human pancreas. Gastroenterology 111 : 1033-8.

4. Galassi E, Birtolo C, Migliori M, Bastagli L, Gabusi V, et al. (2014) A 5-year experience of benign pancreatic hyperenzymemia. Pancreas 43: 874-8.

5. Birtolo C, Migliori M, Drewes AM, Tomassetti P, Imbrogno A, et al. (2017) Benign pancreatic hyperenzymemia: lights on a clinical challenge. Pancreas 46: $5-7$.

6. Berk JE, Kizu H, Wilding P, Searcy RL (1967) Macroamylasemia: a newly recognized cause for elevated serum amylase activity. N Engl J Med 277: 941-6.

7. Warshaw AL, Lee KH (1978) Macroamylasemia and other chronic nonspecific hyperamylasemias: chemical oddities or clinical entities? Am J Surg 135: 488-93.

8. Catanzaro R, Italia A (2012) Pancreatic hyperenzymemia: new advances in the field of clinical-diagnostic approach, with particular attention about Gullo's syndrome. Minerva Med 103: 393-412. 
9. Gullo L, Lucrezio L, Migliori M, Bassi M, Nesticò V, et al. (2008) Benign pancreatic hyperenzymemia or Gullo's syndrome. Adv Med Sci 53: 1-5.

10. Gullo L (2007) Benign pancreatic hyperenzymemia. Digestive and Liver Disease 39: 698-702.

11. Gullo L, Migliori M (2007) Benign pancreatic hyperenzymemia in children. Eur J Pediatr 166: 125-9.

12. Gullo L, Ventrucci M, Barakat B, Migliori M, Tomassetti P, et al. (2003) Effect of secretin on serum pancreatic enzymes and on the Wirsung duct in chronic nonpathological pancreatic hyperenzymemia. Pancreatology 3: 191-4.

13. Yang BL, Wu WC, Su CW, Wu JC, Yeh C, et al. (2015) Healthy Chinese with benign pancreatic hyperenzymemia. J Chin Med Assoc 78: 623-6.

14. Valente R, Antonelli M, Piciucchi M, Federici GF, Signoretti M, et al. (2013) Celiac disease and CFTR mutations in patients with chronic asymptomatic pancreatic hyperenzymemia. Am J Gastroenterol 108: 618.

15. Gullo L, Mantovani V, Manca M, Migliori M, Bastagli L, et al. (2005) Mutations of the CFTR gene in idiopathic pancreatic hyperenzymemia. Pancreas 31: 350-2. 16. Gullo L, Salizzoni E, Serra C, Calculli L, Bastagli L, et al. (2006) Can pancreatic steatosis explain the finding of pancreatic hyperenzymemia in subjects with dyslipidemia? Pancreas 33: 351-3.

17. Gullo L, Laghi L, Migliori M, Lucrezio L, Bianchi P, et al. (2008) SPINK1 and PRSS1 mutations in benign pancreatic hyperenzymemia. Pancreas 37: $31-5$.

18. Kume K, Masamune A, Mizutamari H, Kaneko K, Kikuta K, et al. (2005) Mutations in the serine protease inhibitor Kazal Type 1 (SPINK1) gene in Japanese patients with pancreatitis. Pancreatology 5: 354-60.

19. Perez M, Colina N, Daoud G, Bracho V, Yañez R, et al. (2016) Familial benign pancreatic hyperenzymemia: Sidrome de Gullo. About a case [Hiperenzimemia pancreatica benigna familiar: Sidrome de Gullo. A proposito de un caso]. Revista Gen 70: 23-7.

20. Martinez J, Gomez A, Palazon JM, Gutierrez A, Perez-Mateo M (1997) Asymptomatic chronic hyperamilasemia of unknown origin: an infrequent entity? Gastroenterology 112: 1057. 